\title{
DENGUE, CHIKUNGUNYA E EBOLA: VIROSES AMBIENTAIS
}

\author{
Thereza Cristina Ferreira Camello \\ Biomédica - Doutora em Ciências Médicas - Microbiologista - Hospital Universitário Pedro Ernesto - \\ Universidade do Estado do Rio de Janeiro - UERJ/ OUERJ/ ONU/ UN-Habitat \\ $\bowtie$ therezacamello@gmail.com
}

\begin{abstract}
Resumo:
Várias viroses emergentes ou reemergentes podem ser veiculadas por mosquitos. Aedes aegypti e Aedes albopictus, os mesmos que transmitem o vírus da dengue e da febre amarela, podem disseminar o vírus Chikungunya que este ano no Brasil já fez cerca de 1000 casos confirmados. A doença tem parâmetros semelhantes aos da Dengue, e embora a taxa de letalidade seja muito baixa, sequelas podem permanecer no individuo por um ano. Em 2014 a partir de setembro o mundo observou perplexo a ressurgência de um vírus hemorrágico letal, em uma das piores epidemias já ocorridas no continente africano. $\mathrm{O}$ vírus Ebola atingiu mais de 6000 pessoas. Estudos no sentido de melhorar as estratégias de contenção da disseminação de vetores e dos vírus devem ser estabelecidas, enquanto aguardamos a produção de vacinas eficazes. O mundo não é imune a uma infecção endêmica, localizada no interior de um continente e não estamos preparados para atender uma demanda deste porte.
\end{abstract}

Palavras-chave: Epidemias, Viroses, Dengue, Chikungunya, Ebola.

\section{DENGUE, CHIKUNGUNYA AND EBOLA: ENVIRONMENTAL VIRUSES}

\begin{abstract}
:
Several emerging viruses or reemerging can be transmitted by mosquitoes. Aedes aegypti and Aedes albopictus, the same that transmit the dengue virus and yellow fever, Chikungunya can spread the virus this year in Brazil has left some 1,000 confirmed cases. The disease has parameters similar to Dengue, and although the mortality rate is very low, sequelae may remain in the individual for a year. In 2014 from September perplexed the world watched the resurgence of a deadly hemorrhagic virus in one of the worst epidemics have occurred in Africa. The Ebola virus has reached more than 6000 people. Studies to improve the containment strategies of dissemination of vectors and viruses should be established, as we await the production of effective vaccines. The world is not immune to an endemic infection, located within a continent and we are not prepared to meet the demands of this riding.
\end{abstract}

Palavras-chave: Outbreak, Viruses, Dengue, Chikungunya, Ebola

\section{As Doenças, Vetores e Sintomas}

Todos os anos, no Brasil, a chegada do verão traz o encontro de uma epidemia viral transmitida por um mosquito, o Aedes aegypti, este ano além do vírus da dengue temos a entrada no país do vírus da febre Chikungunya, também transmitida pela picada de mosquitos infectados, como Aedes aegypti e Aedes albopictus, os mesmos que transmitem o vírus da dengue e da febre amarela, motivo pelo qual essa virose conseguiu recentemente chegar ao Brasil (Figura 1). 
Figura 1. Imagens das duas espécies de mosquito que podem abrigar os vírus da Febre Chikungunya e Dengue.

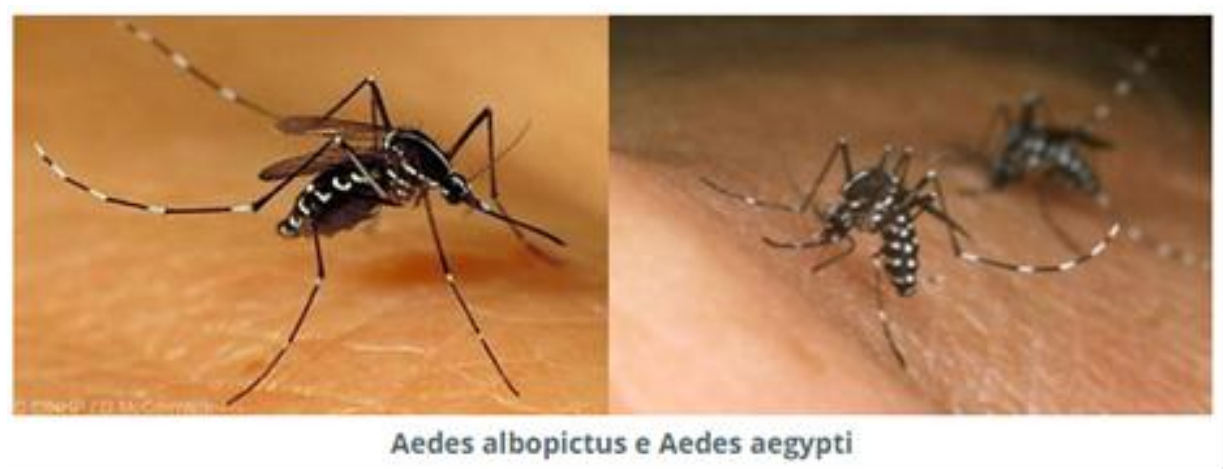

FONTE: http://www.mdsaude.com/2012/04/fotos-mosquito-dengue.html <Acessado em $07 / 12 / 2014>$

A espécie A. albopictus prospera em uma ampla gama de locais de reprodução cheias de água, incluindo cascas de coco, casca de cacau, tocos de bambu, buracos de árvores e piscinas naturais, além de recipientes artificiais, tais como pneus de veículos e pires sob vasos de plantas. Esta diversidade de habitats explica a abundância de A. albopictus em áreas rurais, bem como áreas peri-urbanas e parques da cidade. A. aegypti está mais associada com a habitação humana e usa os locais de reprodução de interior, incluindo vasos de flores, vasos de armazenamento de água e caixas d'água de concreto em casas de banho, bem como os mesmos habitats artificiais ao ar livre como A. albopictus. Ambos A. aegypti e A. albopictus têm sido implicados em grandes surtos de Chikungunya. Considerando A. aegypti que esteja dentro dos trópicos e sub-trópicos, A. albopictus também ocorre em regiões temperadas e mesmo frias. Nas últimas décadas A. albopictus se espalhou da Ásia para se estabelecer em áreas da África, Europa e Américas.

Fatores como a globalização, pela facilidade e rapidez de locomoção, além das modificações de habitat causadas pela invasão humana em locais antes reservados aos diversos tipos de animais, e às crescentes alterações climáticas vem forçando a dispersão de insetos em diversos tipos de ambientes.

Tal fato obriga a intensificar os esforços no sentido não só de conseguirmos metodologias preventivas através de vacinas eficientes, mas também de controle biológico para a diminuição na propagação dos mosquitos, além das ações preventivas básicas quanto à erradicação de locais de proliferação dos mesmos (Figura 2). 
Figura 2. Ações preventivas no combate a larvas de mosquitos.

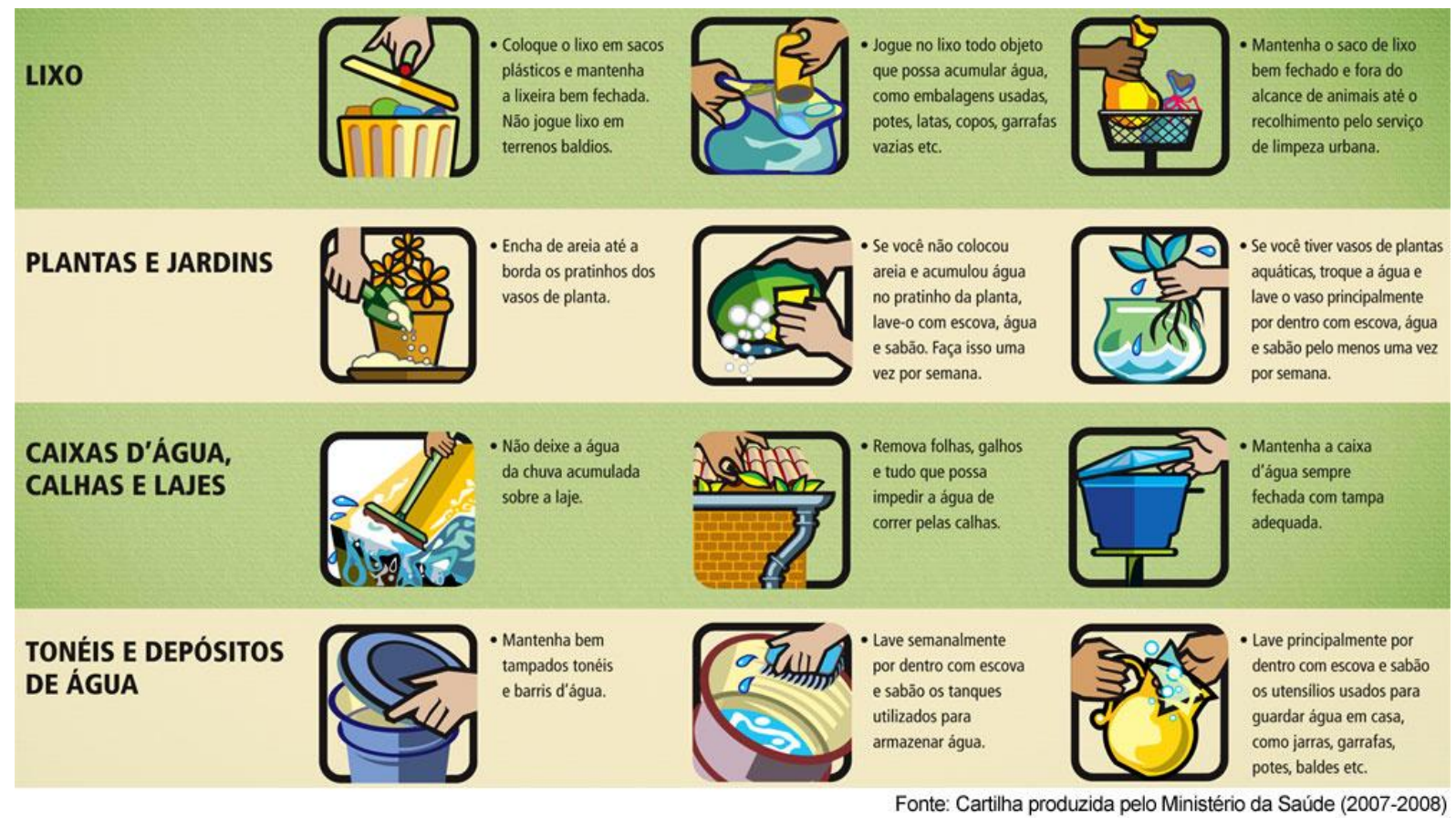

FONTE: MINISTÉRIO DA SAÚDE. 2007/2008

Dengue é uma doença viral que se espalha rapidamente no mundo, causada por um arbovírus da família flaviviridae (Figura 3).

Figura 3. Microfotografia eletrônica do Virus da Dengue

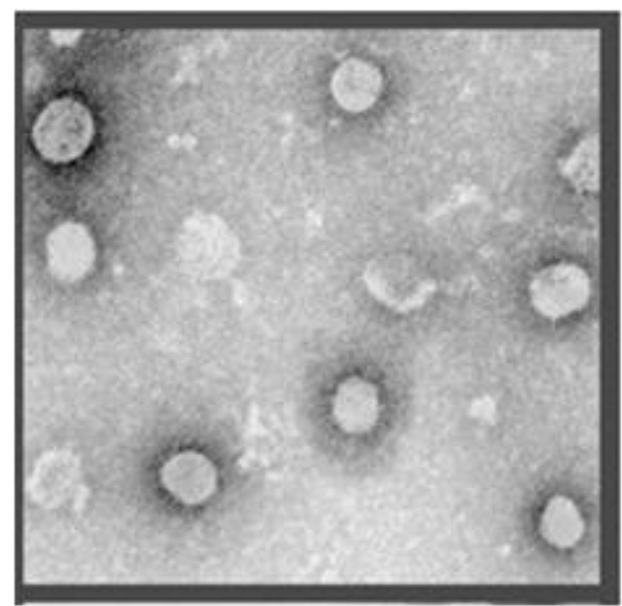

FONTE: http://cienciahoje.uol.com.br/noticias/2012/03/virus-contra-a-dengue $<$ Acessado em 07/12/2014>

Nos últimos 50 anos, a incidência da Dengue, aumentou 30 vezes, com ampliação da expansão geográfica para novos países e, na presente década, para pequenas cidades e áreas 
rurais. É estimado que 50 milhões de infecções por dengue ocorram anualmente e que aproximadamente 2,5 bilhões de pessoas morram em países onde a dengue é endêmica.

Na região das Américas, a doença tem se disseminado com surtos cíclicos ocorrendo a cada 3/5 anos. No Brasil, a transmissão vem ocorrendo de forma continuada desde 1986, intercalando-se com a ocorrência de epidemias, geralmente associadas com a introdução de novos sorotipos em áreas anteriormente indenes ou alteração do sorotipo predominante. $\mathrm{O}$ maior surto no Brasil ocorreu em 2013, com aproximadamente 2 milhões de casos notificados. Atualmente, circulam no país os quatro sorotipos da doença, dos quais o tipo 4 caracteriza a forma hemorrágica, a mais grave e potencialmente fatal. (Figura 4).

Figura 4. Comparação da sintomatologia da Dengue Clássica e Hemorrágica.

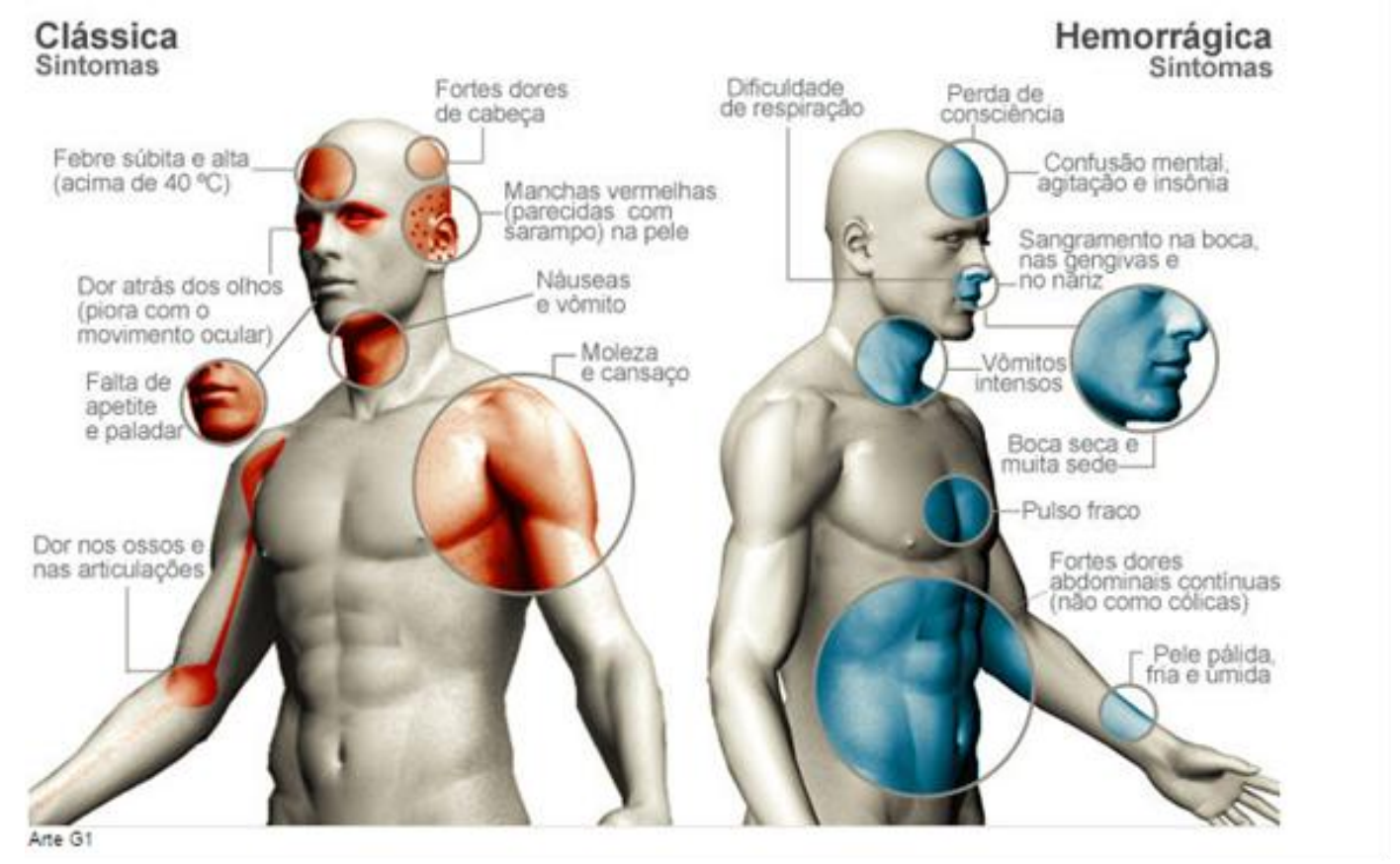

FONTE: http://www.dengue.org.br/dengue_sintomas.html <Acessado em 07/12/2014>

A origem do estranho nome Chikungunya é africana. No idioma makonde, significa “aqueles que se dobram”. É uma referência à postura dos doentes. Com dores articulares fortíssimas, os infectados andam curvados. A doença é causada por um um vírus RNA do gênero Alfavírus (Figura 5). 
Figura 5. Virus Chikungunya (Photo: Marion Sourisseau, Marie-Christine Prévost, Olivier Schwartz, Institut Pasteur Paris.

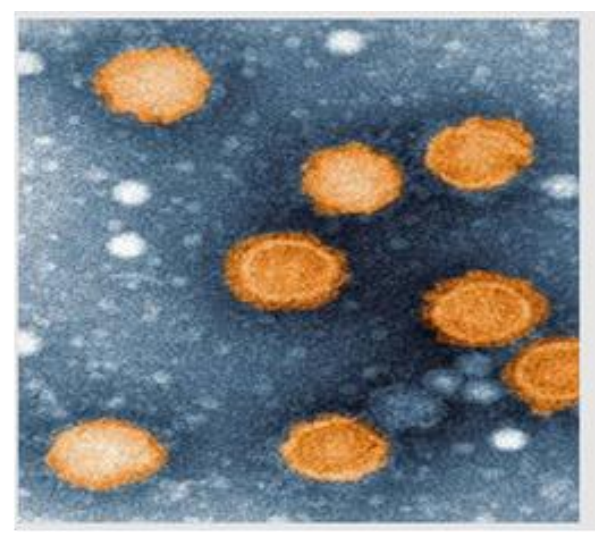

FONTE: http://www.esculape.com/infectio/chikungunya_2007_run.html <Acessado em $07 / 12 / 14>$

A doença pelo vírus Chikungunya, pode causar febre alta, dores musculares, nas articulações e dor de cabeça, a semelhança da dengue, embora quase $30 \%$ dos casos posam ser assintomáticos. Não costuma resultar em morte, mas a dor articular pode durar meses ou anos e pode se tornar uma causa de dor crônica e incapacidade. Não há tratamento específico, nem qualquer vacina para preveni-la. Enquanto se aguarda o desenvolvimento de uma vacina, a única forma eficaz de prevenção é proteger os indivíduos contra picadas de mosquito.

Embora a transmissão através da picada de mosquito seja responsável por praticamente todos os casos, há outras formas possíveis de se contaminar com o Vírus Chikungunya. Uma delas é a chamada transmissão vertical, que ocorre da mãe para o bebê durante o parto. Até onde se sabe o vírus não causa má-formação no feto, pois, aparentemente, a transmissão não ocorre dentro útero, mas sim no momento do parto, seja ele natural ou por cesariana.

Os recém-nascidos contaminados costumam desenvolver a doença entre 3 a 7 dias, e o quadro clínico costuma ser bem mais grave que nos adultos. Não há evidências de transmissão pelo aleitamento materno. Acidentes com agulhas contaminadas ou transfusão de sangue são vias potenciais vias de contaminação e o transplante de órgãos também é forma possível de transmissão do vírus.

De acordo com a OMS, desde 2004, o vírus havia sido identificado em 19 países. A partir do final de 2013, foi registrada transmissão autóctone (dentro do mesmo território) em 
vários países do Caribe, em março de 2014, na República Dominicana e Haiti, sendo que, até então, só África e Ásia tinham circulação do vírus (Figura 6).

Figura 6. Distribuição Mundial do Virus chikungunya.

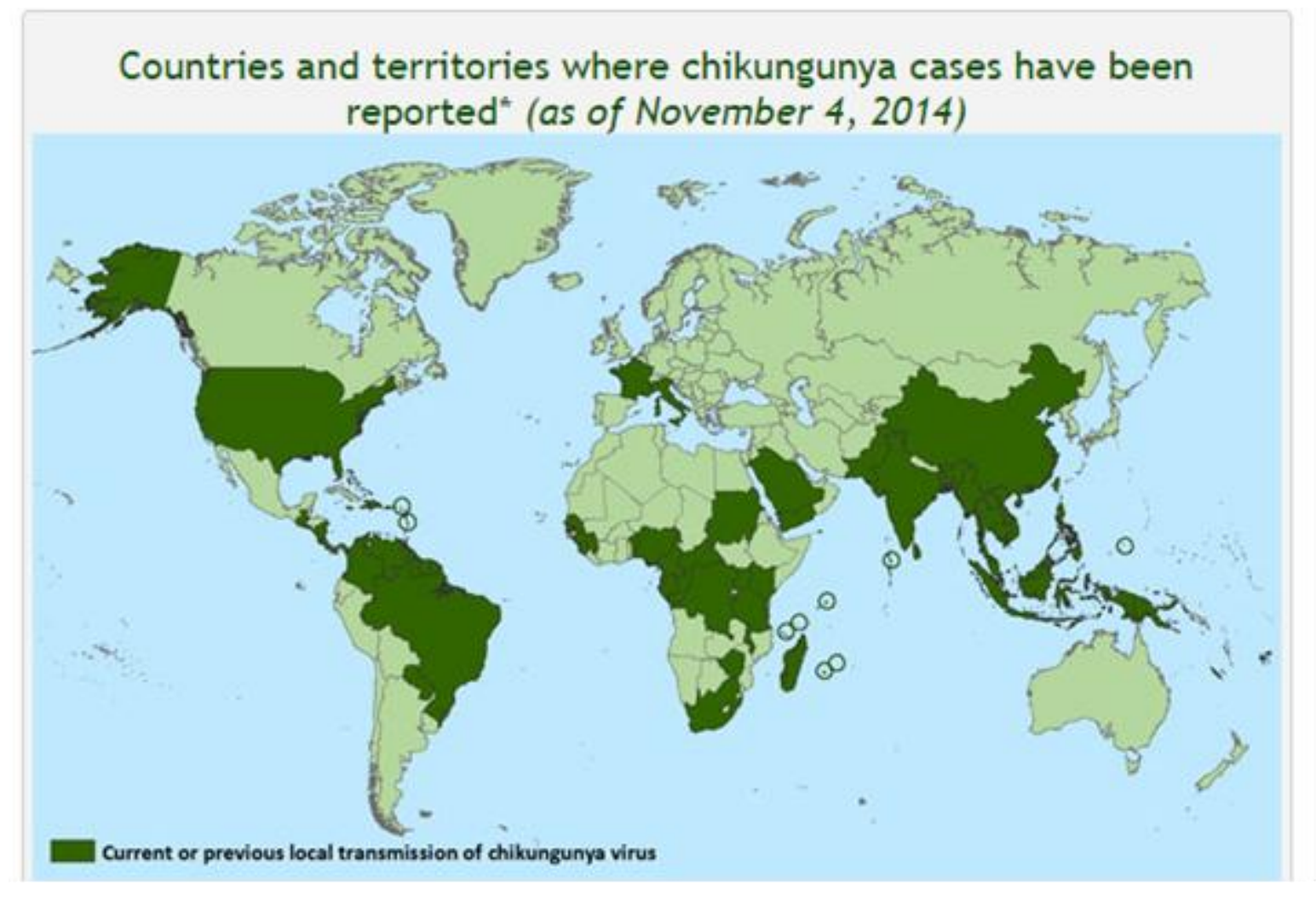

FONTE: http://www.cdc.gov/chikungunya/geo/index.html <Acessado em $07 / 12 / 2014>$

No Brasil, os primeiros casos de transmissão do vírus Chikungunya foram identificados em Setembro de 2014. Até então, todos os casos conhecidos eram importados, adquiridos por brasileiros que haviam viajado para áreas endêmicas. Como era esperado, a combinação entre a elevada prevalência dos mosquitos Aedes aegypti e Aedes albopictus no território brasileiro e a ausência de anticorpos contra o novo vírus entre a população fez com que rapidamente surgissem surtos da febre em diferentes regiões do país.

Em pouco mais de um mês, mais de 1000 casos foram notificados em todo o Brasil.

O Ministério da Saúde registrou, até o dia 25 de outubro de 2014, 828 casos de Febre Chikungunya no Brasil, sendo 155 confirmados por critério laboratorial e 673 por critério clínico-epidemiológico. Do total, são 39 casos importados de pessoas que viajaram para 
países com transmissão da doença, como República Dominicana, Haiti, Venezuela, Ilhas do Caribe e Guiana Francesa. Os outros 789 foram diagnosticados em pessoas sem registro de viagem internacional para países onde ocorre a transmissão. Destes casos, chamados de autóctones, 330 foram registrados no município de Oiapoque (AP), 371 em Feira de Santana (BA), 82 em Riachão do Jacuípe (BA), dois em Salvador (BA), um em Alagoinhas (BA), um em Cachoeira (BA), um em Amélia Rodrigues/BA e um em Matozinhos (MG).

A dengue e a febre Chikungunya partilham de várias semelhanças, veja a (Figura 7).

Figura 7. Comparação entre Dengue e Chikungunya

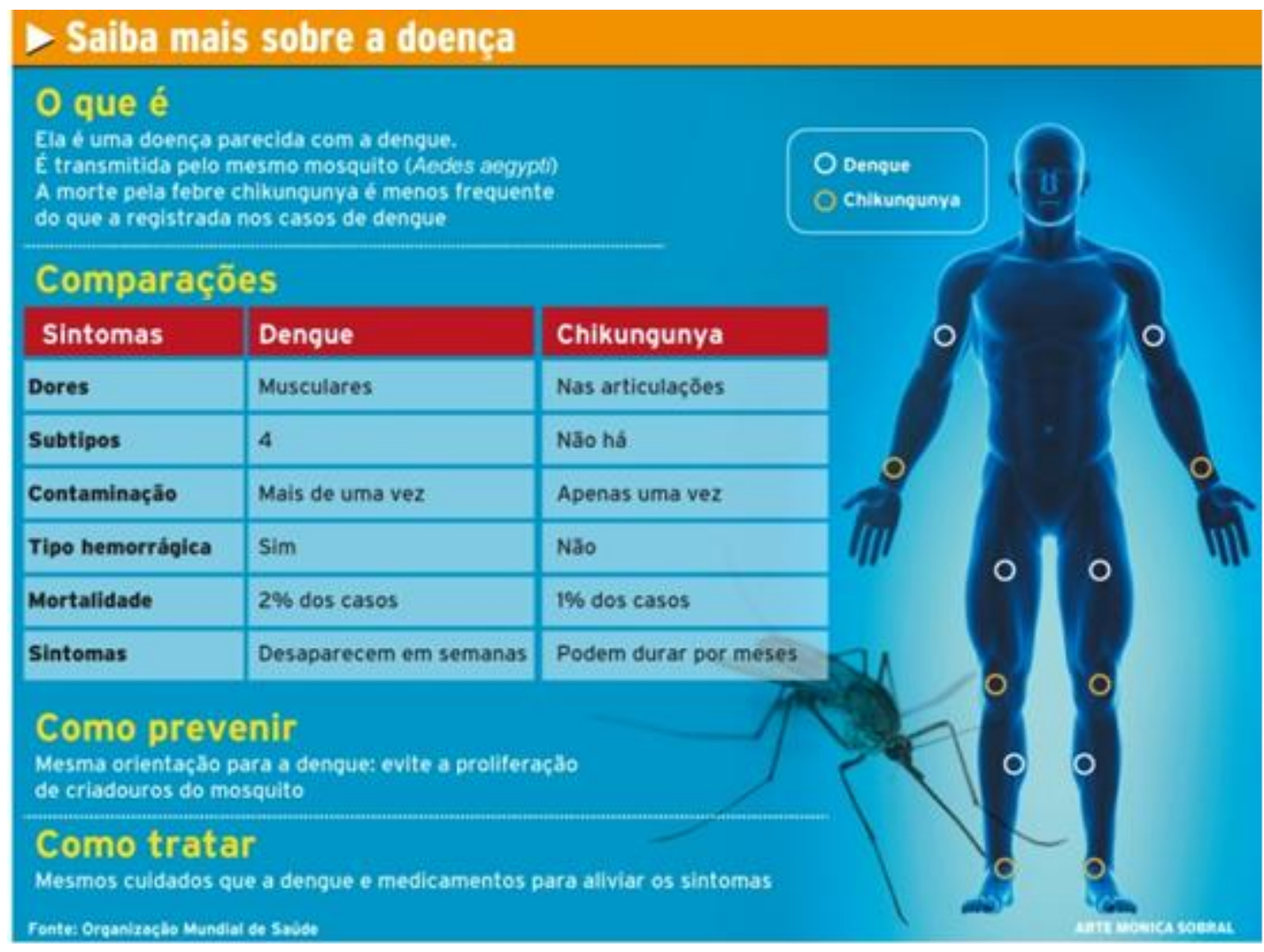

FONTE: OMS. 2014

Em alguns casos, pode ser bastante difícil fazer o diagnóstico diferencial somente através dos sinais e sintomas. A principal diferença é o acometimento das articulações. A dengue até pode causar dor articular, mas ela não costuma ser tão importante quanto a dor muscular ou a dor nos olhos. Na febre Chikungunya, a poliartralgia é um dos sintomas mais exuberantes e é tipicamente dor das articulações das extremidades (mãos e pés). Outra diferença é o rash cutâneo. Na febre Chikungunya as manchas vermelhas surgem nas primeiras 48 horas, enquanto que na dengue o rash só surge a partir do $3^{\circ}$ ou $4^{\circ}$ dia. 
Na dengue, a queda das plaquetas costuma ser mais grave e eventos hemorrágicos, como machas roxas na pele, sangramento nasal ou de gengiva são bem mais comuns. A evolução para um forma hemorrágica é quase exclusiva da dengue. Após o fim da fase aguda, o paciente com dengue costuma sentir-se cansado por vários dias, enquanto que o paciente com febre Chikungunya queixa-se de dor articular.

Para evitar a desidratação, que é muito comum, indica-se o consumo de 1,5 a 2,0 litros de água por dia. Para o controle da febre e das dores articulares, as drogas mais indicadas são o paracetamol e a dipirona. $\mathrm{O}$ uso de anti-inflamatórios ou aspirina deve ser evitado, pois esses medicamentos aumentam o risco de eventos hemorrágicos.

Não existe vacina, nem remédio específico contra o chikungunya. O tratamento da doença consiste em hidratação e uso de medicamentos para aliviar os sintomas semelhantes aos da dengue. Segundo a Organização Mundial da Saúde, complicações graves são raras, mas em pessoas idosas, a infecção pode contribuir para a morte.

Como se não bastassem as ameaças dos flebótomos, nos deparamos com um flagelo desconhecido nas Américas, porém de ocorrência endêmica em algumas regiões africanas, o vírus Ebola, da família Filoviridae, gênero Ebolavirus (Figura 8).

Figura 8. Microfotografia Eletronica do Virus Ebola

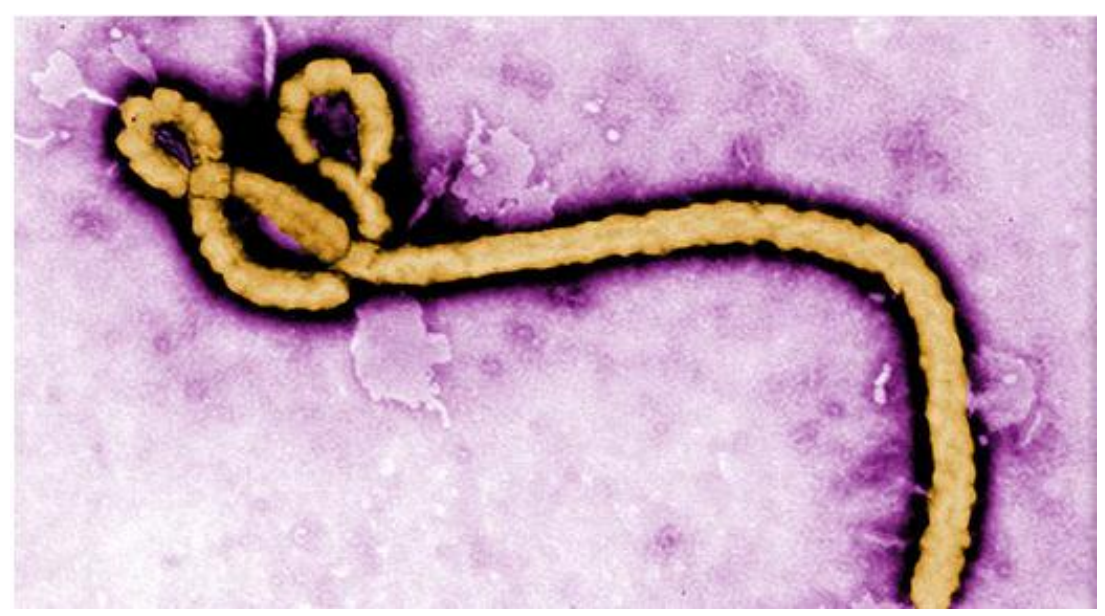

FONTE: $\underline{\text { www.cdc.gov }}<$ Acessado em 07/12/2014>

Em 2014, a possibilidade de uma pandemia sensibilizou o mundo inteiro, órgãos como Médicos Sem Fronteiras (MSF), Centers of Diseases Control and Prevention (CDC) e Organização Mundial de Saúde (OMS), não mediram esforços no sentido de enviar seus 
agentes, para tentar aplacar a fúria viral. Por muitas vezes os esforços pareciam terem logrado, porém a partir do inicio do mês de novembro, começou-se a ver um leve declínio que vem se tornando constante no número de infecções e um aumento significativo nas recuperações dos indivíduos infectados.

Talvez, pelo próprio curso da doença, aliado a presença de melhores condições de higiene e alimentação, a verdade é que o pior já passou, porém, ficou uma grande lição - o mundo não é imune a uma infecção endêmica, localizada no interior de um continente e não estamos preparados para atender uma demanda desta monta - Quer por desconhecimento das particularidades da biologia do agente, dos possíveis vetores ou hospedeiros, ou ainda pela falta de recursos específicos e/ou tecnologias aplicáveis, sem esquecer que em uma população que nunca entrou em contato com o agente, a dispersão da infecção seria bastante acentuada.

O número de óbitos provocados pela atual epidemia de Ebola atinge a casa dos 6000, mas segundo a própria OMS estes números podem estar subestimados.

A primeira vez que o vírus Ebola surgiu foi em 1976, em surtos simultâneos em Nzara, no Sudão, e em Yambuku, na República Democrática do Congo, em uma região situada próximo do Rio Ebola, que dá nome à doença. Morcegos frutívoros são considerados os hospedeiros naturais do vírus Ebola. A aparição da doença é relacionada a relatos de infecção pelo manejo de chimpanzés, gorilas, morcegos, macacos, antílopes e porcosespinhos infectados encontrados mortos ou doentes na floresta.

Primeiramente, o vírus foi associado a um surto de 318 casos de uma doença hemorrágica no Zaire (hoje República Democrática do Congo), em 1976. Dos 318 casos, 280 pessoas morreram rapidamente. No mesmo ano, 284 pessoas no Sudão também foram infectadas com o vírus e 156 pessoas morreram.

O Ebola pode ser transmitido por animais e humanos. Não é uma doença transmitida pelo ar. A transmissão de humanos para humanos se dá por meio do contato com sangue, secreções ou outros fluidos corpóreos de uma pessoa infectada com Ebola e somente quando o paciente apresenta sintomas da doença. O contato direto com cadáveres, durante os rituais fúnebres, por exemplo, é uma das principais formas de transmissão da doença. Os funerais são práticas importantes nas comunidades afetadas por essa epidemia e envolvem pessoas tocando e lavando o corpo, em demonstração de amor à pessoa falecida. Nas últimas horas antes da morte, o vírus se torna extremamente contagioso e, por isso, o risco de transmissão a 
partir do cadáver é muito maior. Por essas razões, garantir a segurança dos funerais é parte crucial da administração de um surto por vírus Ebola.

Frequentemente, profissionais de saúde e agentes comunitários locais são infectados enquanto tratam pacientes com Ebola, especialmente no início de uma epidemia. Isso acontece por meio do contato próximo com os doentes sem o uso de luvas, máscaras ou óculos de proteção.

O vírus tem cinco cepas (origem ou linhagem). A taxa de mortalidade do vírus varia entre $25 \%$ e $90 \%$, dependendo da cepa. O mais letal deles, chamado Zaire, é predominante na epidemia, que desde março de 2014 atinge a África Ocidental e é considerada a maior da história.

Ao longo dos primeiros sete primeiros meses da epidemia deste ano, MSF montou seis centros de tratamento de Ebola - dois na Guiné, dois na Libéria e dois em Serra Leoa - e mobilizou mais de 3.300 profissionais. Há cinco espécies do vírus Ebola: Bundibugyo, Costa do Marfim, Reston, Sudão e Zaire, nomes dados a partir de seus locais de origem. Quatro dessas cinco cepas causam a doença em humanos. Embora o vírus Reston possa infectar humanos, nenhuma enfermidade ou morte foi relatada por esta espécie.

O Ebola pode ser transmitido por animais e humanos. Não é uma doença transmitida pelo ar. A transmissão de humanos para humanos se dá por meio do contato com sangue, secreções ou outros fluidos corpóreos de uma pessoa infectada com Ebola e somente quando o paciente apresenta sintomas da doença. $\mathrm{O}$ contato direto com cadáveres, durante os rituais fúnebres, por exemplo, é uma das principais formas de transmissão da doença. Os funerais são práticas importantes nas comunidades afetadas por essa epidemia e envolvem pessoas tocando e lavando o corpo, em demonstração de amor à pessoa falecida. Nas últimas horas antes da morte, o vírus se torna extremamente contagioso e, por isso, o risco de transmissão a partir do cadáver é muito maior. Por essas razões, garantir a segurança dos funerais é parte crucial da administração de um surto por vírus Ebola.

Frequentemente, profissionais de saúde e agentes comunitários locais são infectados enquanto tratam pacientes com Ebola, especialmente no início de uma epidemia. Isso acontece por meio do contato próximo com os doentes sem o uso de luvas, máscaras ou óculos de proteção (Figura 9). 
Figura 9. Traje completo dos profissionais de saúde e ação de descontaminação.

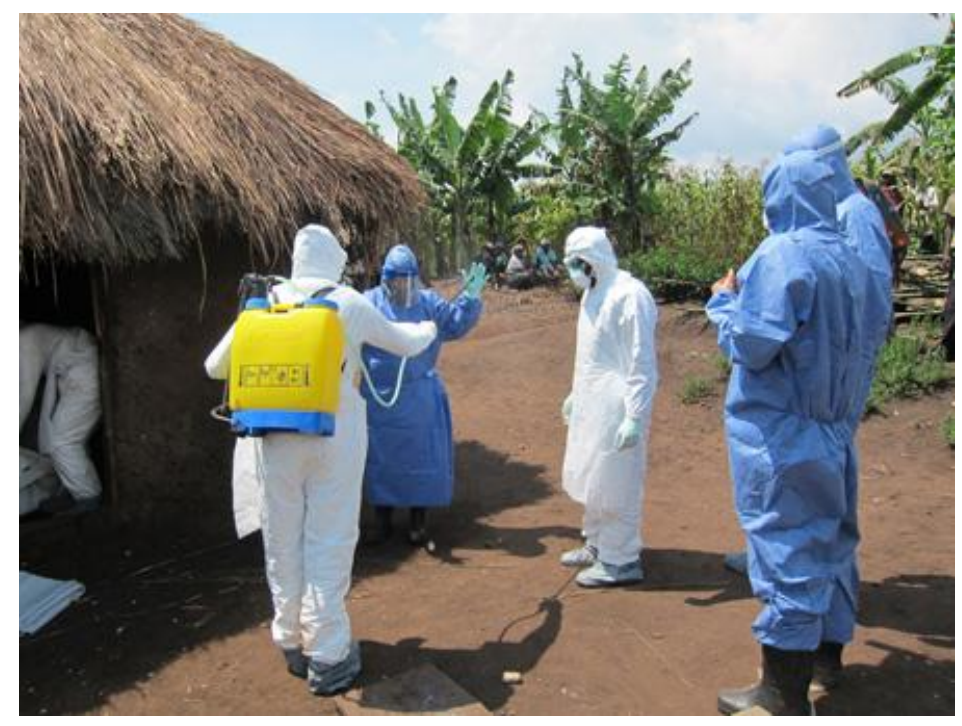

FONTE: $\quad$ http://www.cdc.gov/vhf/ebola/exposure/index.html <Acessado em 07/12/2014>

Os sintomas que caracterizam a doença são a febre repentina; fraqueza; dores musculares e de cabeça, além de inflamação na garganta. Após os sintomas iniciais, o infectado apresenta um quadro com vômitos, diarreia, coceiras, deficiência nas funções hepáticas e renais que culminam com sangramento interno e externo. Os sintomas podem aparecer de dois a 21 dias após a exposição ao vírus. Alguns pacientes podem ainda apresentar erupções cutâneas, olhos avermelhados, soluços, dores no peito e dificuldade para respirar e engolir.

As infecções só podem ser diagnosticadas definitivamente em laboratório, após a realização de cinco diferentes testes. Esses testes são de grande risco biológico e devem ser conduzidos sob condições de máxima contenção.

Como os agentes de saúde estão, particularmente, suscetíveis a contraírem o vírus durante o tratamento dos pacientes, uma das principais prioridades é o treinamento das equipes de saúde para reduzir o risco de contaminação pela doença enquanto estão cuidando de pessoas infectadas. Os profissionais não entram em contato direto com os infectados e usam equipamentos de segurança que vão de botas a óculos de proteção. Parte dos paramentos é incinerada após a saída da área de isolamento.

Apesar das dificuldades para diagnosticar o Ebola nos estágios iniciais da doença, aqueles que apresentam os sintomas devem ser isolados e os profissionais de saúde pública notificados. O tratamento padrão para a doença limita-se à terapia de apoio, que consiste em 
hidratar o paciente, manter seus níveis de oxigênio e pressão sanguínea e tratar infecções que possam aparecer. A terapia de apoio pode continuar, desde que sejam utilizadas as vestimentas de proteção apropriadas até que amostras do paciente sejam testadas para confirmar a infecção. Uma vez que um paciente se recupera do Ebola, ele está imune à cepa do vírus que contraiu.

O fim de um surto de Ebola apenas é declarado oficialmente após o término de 42 dias sem nenhum novo caso confirmado.

\footnotetext{
"O maior desafio é tentar oferecer o melhor tratamento sem ter muitos recursos pra isso. É muito dificil ter de lidar com os pacientes com tanta limitação. Limitação de trabalhar fora de uma estrutura de hospital, de tempo com o paciente, porque não conseguimos ficar muito tempo com a roupa que é muito quente, de estrutura para fazer exames laboratoriais. É muito complicado fazer exames. Não podemos levar equipamentos para dentro do centro porque não dá para levá-los para nenhum outro local depois [, pois eles estariam contaminados]", Médico generalista brasileiro, Paulo Reis. (REIS, 2014, em <http://www.msf.org.br/noticias/epidemia-deebola-medico-brasileiro-fala-sobre-sua-experiencia-com-doenca $>$ )
}

A perspectiva de uma vacina esta em andamento e a partir do primeiro trimestre de 2015 deverá estar sendo testada em humanos, já que os testes em macacos foram bastante promissores. A vacina baseia-se em um adenovírus geneticamente modificado, utilizado como veículo genético para uma proteína do vírus Ebola ("ChAd-Ebola"; ChimpanzéAdenovírus ChAd3-ZEBOV). Os ensaios estão sendo realizados e deverão testar a segurança da vacina e a sua capacidade para induzir uma resposta imune.

Diante de tantas informações e da impossibilidade no momento de erradicar estas doenças, só nos resta usar o conhecimento aprendido para proteger-nos enquanto aguardamos ansiosos a emergência de outro surto viral conhecido ou quem sabe ainda obscuro.

\section{REFERÊNCIAS PARA CONSULTA}

\section{Para saber mais sobre o assunto}

http://ebolanobrasil.com/ebola-transmissao-ebola-sintomas-ebola-tratamentos-ebola-cuidados/

http://www.boasaude.com.br/noticias/10750/o-ebola-no-oeste-africano-os-primeiros-novemeses-de-epidemia-e-suas-projecoes.html/

http://portal.fiocruz.br/pt-br/content/pesquisa-do-ioc-e-instituto-pasteur-alerta-para-risco-deepidemia-de-chikungunya-no-brasil/ 
http://epoca.globo.com/colunas-e-blogs/cristiane-segatto/noticia/2014/10/o-bchikungunyabprimo-da-dengue-deveria-assustar-mais-que-o-bebolab.html

$\underline{\text { http://www.cdc.gov/chikungunya/ }}$

http://veja.abril.com.br/noticia/saude/brasil-registra-828-casos-de-febre-chikungunya/

http://www.paho.org/hq/index.php?Itemid=40931/

http://www.em.com.br/app/noticia/nacional/2014/10/16/interna_nacional,580471/ministerioda-saude-considera-febre-chikungunya-epidemica-em-cidade-da-bahia.shtml/

http://www.phac-aspc.gc.ca/tmp-pmv/notices-avis/notices-avis-eng.php?id=120/

http://portalsaude.saude.gov.br/images/pdf/2014/setembro/16/Perguntas-e-Respostas-sobreChikungunya.pdf/

http://www.cve.saude.sp.gov.br/htm/zoo/informes/IFOUT14_CHIKUNGUNYA.pdf/

http://portalsaude.saude.gov.br/index.php/o-ministerio/principal/secretarias/svs/dengue/

http://portalsaude.saude.gov.br/images/pdf/2014/outubro/27/BE-2014-45--26----Dengue-

SE41-e-CHIKV-SE42.pdf/

http://www.mdsaude.com/2014/11/febre-chikungunya.html/

\section{Material didático para professores}

http://www.ioc.fiocruz.br/dengue/textos/docsprem.html/

http://www.fiocruz.br/ioc/cgi/cgilua.exe/sys/start.htm?sid=45/

http://www.dengue.org.br/dengue_downloads.html/

https://www.youtube.com/watch?v=oHsP-lzPgkU/ 